\title{
Mice Create What-Where-When Hippocampus-Dependent Memories of Unique Experiences
}

\author{
Laetitia Fellini ${ }^{1}$ and Fabio Morellini ${ }^{1,2}$ \\ ${ }^{1}$ Zentrum für Molekulare Neurobiologie Hamburg and ${ }^{2}$ Experimentelle Neuropädiatrie, Universitätsklinikum Hamburg-Eppendorf, 20246 Hamburg, \\ Germany
}

Episodic memory is relevant for auto-consciousness in humans. In nonhuman animals, episodic-like memory is defined when the "what-where-when" content of a unique event forms an integrated cognitive representation that is then deployed during memory retrieval. Here, we aimed at testing episodic-like memories of mice under experimental conditions that allow the analysis of whether and how mice process what-where-when information. Using an ecologically relevant paradigm for spontaneous learning and memory, we show that mice modulate their behavior based on the what, where, and when components of past unique episodes, specifically on previous encounters of conspecifics at a defined location and at a specific time of the day. We also show that learning during this paradigm activated $A r c / A r g 3.1$ mRNA expression in the hippocampus and that stereotactic injection of anisomycin into this region impairs memory consolidation. Thus, hippocampus-dependent episodic-like memories of single experiences are spontaneously created in mice. These findings extend our knowledge of the cognitive capacities of the mouse and suggest that this species can be used as model for studying the mechanisms underlying human episodic memory and related neurological disorders.

\section{Introduction}

Episodic memory is a human cognitive function that allows individuals to "travel back into the past in their own minds" (Tulving, 1972). Degradation of the capacity to store and retrieve episodic memories results from several neuropsychiatric diseases, with dramatic consequences for the affected patients and their families. The original definition of episodic memory has been linked to autonoetic consciousness (Tulving, 2002), a feature that can be demonstrated only in humans (Griffiths et al., 1999). For nonhuman animals, the definition of episodic-like memory has been proposed. The criterion for episodic-like memory is that a behavioral response should be based on "what" occurred "where" and "when" during a past experience (Clayton and Dickinson, 1998). What-where-when memory as a form of episodic-like memory was first proposed in an elegant study on Western scrub jays (Clayton and Dickinson, 1998), and later in rodents such as rats (Zhou and Crystal, 2009) and meadow voles (Ferkin et al., 2008). In the last decades, the mouse has become a relevant model for human cognitive functions. Traditional memory paradigms designed for the mouse are concerned with the question of what was experienced and eventually where an event was experienced. To model human episodic memory, protocols

Received May 11, 2012; revised 0ct. 19, 2012; accepted 0ct. 31, 2012.

Author contributions: L.F. and F.M. designed research; L.F. and F.M. performed research; L.F. and F.M. analyzed data; L.F. and F.M. wrote the paper.

This work was supported in part by the Sonderforschungsbereich 936 of the Deutsche Forschungsgemeinschaft. We thank I. Meier for help performing and analyzing the experiment on mRNA expression by real-time RT-PCR and D. Isbrandt for comments on the manuscript. We thank M. Schachner and D. Isbrandt for providing support and facilities for experiments.

Correspondence should be addressed to Fabio Morellini, Experimentelle Neuropädiatrie, Martinistrasse 52, 20246 Hamburg, Germany. E-mail: fabio.morellini@enp.org.

DOI:10.1523/JNEUROSCI.2280-12.2013

Copyright $\odot 2013$ the authors $\quad 0270-6474 / 13 / 331038-06 \$ 15.00 / 0$ have been designed that require mice to also use temporal cues for the localization of a target during a spatial learning task, such as in the delayed match-to-place protocol in the water maze test (Staddon, 1984) or the novelty preference paradigm designed by Dere et al. (2005). Notwithstanding these efforts to model human episodic memory in mice, it is questionable whether these paradigms fulfill the criteria for episodic-like memory, because they require either several trials and sessions, or spatial preference results from familiarity, or the time component can be solved based on the calculation of how long ago and not when a certain event took place (Clayton et al., 2003a).

Here, we established a paradigm in which we tested whether male mice are capable of creating memories of what they experienced at a particular time and spatial location. To fulfill the criteria for episodic-like memory, the following criteria should be reached: memory should be formed after an experience, the what and where components of the memory should not be retrieved based on familiarity, nor the when component based on how long ago the event occurred. Finally, mice should modulate their behavioral responses depending on the integrated what-wherewhen representation.

\section{Materials and Methods}

Animals and husbandry. C57BL/6J and CD-1 mice aged between 3 and 5 months were kept in a vivarium with an inverted 12:12 light:dark cycle (light off at 0700$)$ under standard housing conditions $\left(23 \pm 1{ }^{\circ} \mathrm{C}, 40-\right.$ $50 \%$ humidity, food and water ad libitum). Male mice were isolated $10 \mathrm{~d}$ before starting the experiments, which were performed in a room adjacent to the vivarium and illuminated by red light. Prior to testing, none of the mice had ever contacted conspecific females after the age of $21 \mathrm{~d}$. Care was taken to minimize pain or discomfort for the animals. Experiments were conducted in accordance with the German and European Community laws on protection of experimental animals and approved by the local authorities of the City of Hamburg. 
A

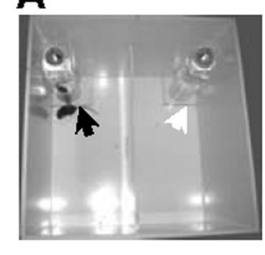

B

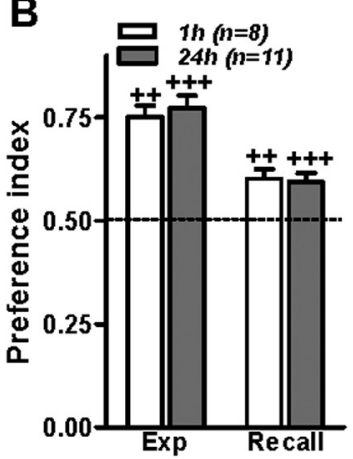

C

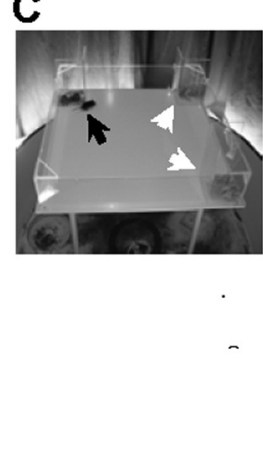

D

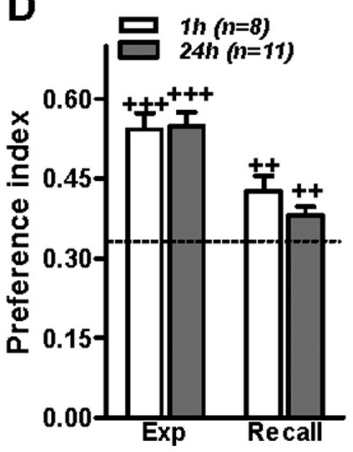

Figure 1. Memory of where. Mice display short- and long-term preference for the female location. $\boldsymbol{A}, \boldsymbol{C}$, Pictures of the compartmented $(\boldsymbol{A})$ and open $(\boldsymbol{C})$ arenas. The preference index for the female's location (black arrow) versus the other locations (white arrows) was calculated: an index higher than the value that would be expected by mice behaving by chance ( 0.5 and 0.33 for the compartmented and open arenas, respectively, depicted by a dashed line in $\boldsymbol{B}$ and $\boldsymbol{D}$ ) indicates a preference for the female's location. $\boldsymbol{B}, \boldsymbol{D},(57 \mathrm{BL} / 6 \mathrm{~J}$ male mice displayed a preference for the female's location in the compartmented $(\boldsymbol{B})$ and open $(\boldsymbol{D})$ arenas during the experience (Exp) and recall trials performed 1 (white) and 24 (gray) h after the experience trial. ${ }^{++} p<0.01,{ }^{+++} p<0.001$ (Wilcoxon signed-rank test) compared with chance level.

Arenas. The compartmented arena was a square box $(50 \times 50 \mathrm{~cm}$ and $38 \mathrm{~cm}$ high) made of white polyvinyl chloride (PVC). The apparatus was divided into two equal compartments by a white PVC wall with a hole in the middle to allow a mouse to move between the two compartments. A transparent plastic beaker was placed in one corner of each compartment, one of which contained a female mouse during the experience trials (Fig. 1A). Several holes were drilled $1 \mathrm{~cm}$ from the beaker's bottom to allow the male to interact with the female. The open arena was a white, laminated, square, wooden plate bordered by a $10-\mathrm{cm}$-high transparent Plexiglas wall $(79.5 \times 79.5 \mathrm{~cm})$. Transparent Plexiglas walls $(26 \mathrm{~cm}$ high $)$ were added in three of the four corners to create three boxes $(14 \times 14 \mathrm{~cm})$ (Fig. 1C) and three cohabitating female mice were placed in one of them during the experience trials. Holes were drilled at the bottom of these walls so that male mice in the arena could interact with female mice. White light illuminated the compartmented (15 lux) and open (65 lux) arenas.

Experiment 1. Male mice underwent one 20 min experience trial and 1 or $24 \mathrm{~h}$ thereafter one $20 \mathrm{~min}$ recall trial. During the experience trial, mice were placed in the arena with the nostrils contacting the holes of the beaker (when the compartmented arena was used) or box (when the open arena was used) in which the females were located. The recall trial was performed similarly to the experience trial, with the only differences being that females were absent and male mice were placed in the center of the arenas or, in the case of the compartmented arena, at the door between the two compartments. To avoid the presence of female odor during the recall trial, two identical sets of arenas were used for the experience and recall trials. The arenas were surrounded by dark curtains and placed in the same location in the experimental room during the experience and recall trials. Mice could orientate by using geometric information extrapolated from the shape of the arenas (Fellini et al., 2006; Meier et al., 2010; Fellini and Morellini, 2011).

Experiment 2. CD-1 male mice were subdivided into three groups: mice that underwent one experience trial and $24 \mathrm{~h}$ thereafter one recall trial in the compartmented arena (Same Arena group), mice that underwent one experience trial in the compartmented arena and one recall trial in the open arena (Different Arena group), and mice that underwent one experience and recall trial in the compartmented arena without the presence of any female (No Female group). All trials lasted $20 \mathrm{~min}$. Urine markings were collected on Whatman filter paper grade 4 that had been placed on the ground of the arena during the trials and counted under UV light by an experienced observer blind to the grouping.

Experiment 3. Before starting the experiment, C57BL/6J male mice underwent a social defeat protocol to develop submissive behavior toward an aggressive CD-1 male mouse. C57BL/6J male mice were introduced into the cage of a singly housed CD-1 male mouse for 30 min twice a day for 4 consecutive days. During each confrontation, the resident CD-1 mouse promptly and continuously attacked the C57BL/6 J intruder mouse. Each C57BL/6J mouse was always exposed to the same CD-1 mouse, which was also used as social stimulus during the experience trials. Only C57BL/6J mice that displayed typical submissive behavior (e.g., fleeing and upward posture) were tested. Two days after the last confrontation with the aggressive mice, C57BL/6J mice underwent the first of four 20 min experience trials in the compartmented arena (see Fig. $3 A$ ). During Trials 1 and 3, a female mouse was placed inside a beaker in one corner of the maze (Female Experience Trial), whereas during Trials 2 and 4, a dominant CD-1 male was placed in the beaker at the same corner (Dominant Male Experience Trial; see Fig. 3A). C57BL/6J mice were subdivided into two groups to counterbalance the time of the day they experienced either the female or dominant male. One group (Female Early Dark) underwent the Female Experience Trials 1 and 3 2-4 h after the light offset, and the Dominant Male Experience Trials 2 and 4 2-4 h before light onset in the vivarium. Another group (Female Late Dark) performed the Female Experience Trials 1 and 3 2-4 h before light onset, and the Dominant Male Experience Trials 2 and $42-4 \mathrm{~h}$ after light offset. The day after Trial 4, two $10 \mathrm{~min}$ recall trials were performed in the morning (Early Dark Recall Trial) and evening (Late Dark Recall Trial), during which neither a female nor the dominant male were present (see Fig. $3 A$ ).

Learning-induced gene expression. Expression of mRNA for Arc/Arg3.1 induced by learning was analyzed in C57BL/6J mice undergoing a $20 \mathrm{~min}$ experience trial in the compartmented arena (Experience group) and compared with the Open Field and Female groups that served as control for Arc/Arg3.1 mRNA expression induced by novelty and female stimulus, respectively. Mice of the Open Field group were placed in an openfield box ( $50 \times 50 \mathrm{~cm}$ and $38 \mathrm{~cm}$ high) for $20 \mathrm{~min}$. The apparatus was circled by dark curtains and was illuminated by white light (65 lux). Mice in the Female group were placed in a cage $(40.5 \times 24.5 \mathrm{~cm}$ and $15.5 \mathrm{~cm}$ high) with fresh bedding and that was divided into two equal compartments by a wire net going from the top to the floor of the cage. The male mouse stayed in one of these two compartments for $3 \mathrm{~d}$ with food and water ad libitum. Then, three C57BL/6J adult females were placed in the adjacent compartment for $20 \mathrm{~min}$. Once the $20 \mathrm{~min}$ elapsed, mice from each group were returned to their home cage in the animal facility for 20 min before being killed for tissue preparation for the quantitative realtime RT-PCR. Tissue preparation and quantitative real time RT-PCR were performed as described previously (Meier et al., 2010). The following primers, designed with Primer Express version 2.0 (Applied Biosystems), were used: full-length Arc/Arg3.1 (forward 5'-CGG CAT CTG TTG ACC GAA GT-3'; reverse 5'-GGCACGTAGCCGTCCAAGT-3'); hypoxanthine guanine phosphoribosyl transferase (forward $5^{\prime}$-GTT CTT TGC TGA CCT GCT GGA- ${ }^{\prime}$; reverse $5^{\prime}$-TCC CCC GTT GAC TGA TCA TT-3'); Actin (forward 5' ${ }^{\prime}$-TCC TGT GGC ATC CAT GAA ACT; reverse $5^{\prime}$-TTC TGC ATC CTG TCA GCA ATG-3'). Specificity was validated by sequencing the amplified products. Triplicate reactions were prepared for each sample along with a no-template and a minus-reversetranscriptase control. Triplicates were validated when technical error was 
$<0.5$ threshold cycle (CT). CTs were determined with SDS 2.0 software (Applied Biosystems) for each sample and normalized using the mean CT for hypoxanthine phosphorybosyl transferase and actin as a reference for overall expression level.

Stereotactic anisomycin injection. Under isoflurane anesthesia and using standard stereotaxic procedures, bilaterally stainless-steel guide cannulas (24-gauge) were implanted into the cortex $1.2 \mathrm{~mm}$ above the dorsal hippocampus. The following coordinates were used: (AP) $-1.8 \mathrm{~mm}$; (ML) $\pm 1.5 \mathrm{~mm}$; (DV) $-1.2 \mathrm{~mm}$, according to Franklin and Paxinos (1997). The cannulas were fixed on the skull by means of dental cement (carboxylate cement; Speiko). The experiment started after a recovery period of $7 \mathrm{~d}$. After a 20 min experience trial in the compartmented arena, mice received a bilateral intrahippocampus injection of anisomycin or $\mathrm{NaCl}$ immediately after the learning session. Shortly before injection, anisomycin

$(100 \mu \mathrm{g} / \mu \mathrm{l}$; Sigma-Aldrich) was dissolved in $1 \mathrm{M} \mathrm{HCl}$ diluted in $\mathrm{NaCl}$ and adjusted to a $\mathrm{pH}$ of 7.0/7.4 with $1 \mathrm{M} \mathrm{NaOH}$. At the end of the experience trial, an injection cannula (30-gauge) was connected to a $2 \mu$ l Hamilton syringe via polypropylene tubing and inserted extending $1.2 \mathrm{~mm}$ beyond the end of the guide cannula. Then, anisomycin or $\mathrm{NaCl}(0.5 \mu \mathrm{l})$ were injected into the hippocampus at a constant flow rate $(0.2 \mu \mathrm{l} / \mathrm{min})$ via a micropump. After injection was completed, the injection cannula was left in place for $90 \mathrm{~s}$ to allow diffusion. The procedure was then repeated for the second cannula on the controlateral side. After $24 \mathrm{~h}$, mice underwent a 20 min recall trial, after which they were immediately decapitated. Brains were removed and frozen at $-20^{\circ} \mathrm{C}$. Cannula placements were determined by serial coronal section $(25 \mu \mathrm{m})$ stained with cresyl-violet and only data from properly implanted mice were analyzed.

Behavioral analysis. All trials were video recorded and paths were digitalized and analyzed with the software Ethovison (Noldus) as described previously (Meier et al., 2010). The software used the middle point of the mouse body to calculate occupancy and distance moved. For experience and recall trials, the percentage of time spent in a zone $(6 \mathrm{~cm}$ width) surrounding the beakers (compartmented arena) or boxes (not compartmented arena) was calculated. The zones at the female's location were designated as "target," and the other zones were designated as "control." The preference index corresponded to the proportion of time spent in the target zone relative to the total time spent in target and control zones.

Statistics. Wilcoxon-signed rank test was used to compare the preference index during the experience and recall trials against the chance level ( 0.5 for the compartmented arena and 0.33 for the open arena). Comparisons between groups were performed with the Mann-Whitney's $U$ test or the Kruskal-Wallis test followed by the Duncan post hoc test when appropriate. In Experiment 3, the preference index of the two learning groups during the two recall trials was analyzed using a mixed two-way ANOVA for repeated measurements having group (Female Early Dark vs Female Late Dark) as between-groups factor and time (Early Dark Recall vs Late Dark Recall) as within-groups factor, followed by Newman-Keuls post hoc analyses when appropriate. All tests were two-tailed and level of significance was set at $p<0.05$. Data are presented as mean with SEM.

\section{Results}

\section{Memory of where (Experiment 1)}

Following the assumption that knowing the location of potential mating partners is extremely adaptive, we tested whether male mice preferentially spent more time at a location where they had previously experienced the presence of adult female mice. During a 20 min experience trial, C57BL/6 male mice were placed in an arena subdivided into two compartments. A female mouse was located in a beaker at one corner of one compartment (Fig. 1A). During the experience trial, all mice spent significantly more time

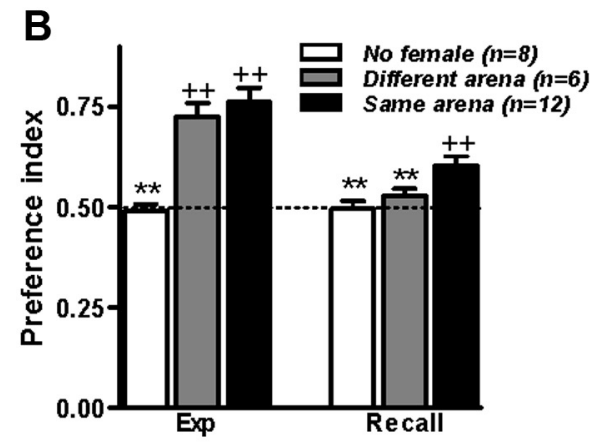
When, 1 or $24 \mathrm{~h}$ later, the male mice were placed in the arena again for a $20 \mathrm{~min}$ recall trial, but without the female mouse, they preferentially stayed in the target zone, i.e., in the location previously occupied by the female (Fig. $1 B$ ). Similar results were observed using a new cohort of C57BL/6J male mice tested in an open arena in which three female mice were placed behind Plexiglas walls at one corner of the arena (Fig. 1C), indicating that the spatial memory may develop under different environmental conditions. One and $24 \mathrm{~h}$ after the experience trial, male mice spent more time at the box where the female mice were confined compared with the other two boxes in the arena (Fig. 1D). Hence, mice are capable of learning and remembering the location of female mice after a single 20 min experience.

\section{Memory of what (Experiment 2)}

It was argued that the emergence of a spatial preference during a recall trial could be expressed based on mere familiarity (Griffiths et al., 1999; Clayton et al., 2003b). It is indeed accepted that mice tend to investigate less familiar stimuli or places (Dere et al., 2007). Specifically, during the recall trial of Experiment 1, familiarity is expected to induce avoidance of the target zone in which mice spent the majority of time during the experience trial. Nevertheless, we could not exclude that familiarity induced a preference for the more familiar stimulus in our paradigm. Therefore, we quantified a behavioral parameter that, based on what is known about the biology of this species, could be interpreted as induced by female mice. Mice mark their territory with small drops of urine containing pheromones that convey a variety of social information and affect the reproductive condition of females (Bronson, 1976; Hurst, 1990). While both male and female mice mark in response to changes in their familiar environment (Hurst, 1989), male urine marking is strongly activated in the presence of conspecifics and in particular females (Reynolds, 1971; Maruniak et al., 1975). In Experiment 2, we tested whether male mice expressed enhanced urine marking during the recall trial as indication that they associated the arena with the females. For this purpose, we used CD-1 male mice that, among the laboratory mouse strains, have well maintained the territorial behavioral repertoire of the wild house mouse (Parmigiani et al., 1999). Similarly to C57BL/6 J mice, CD-1 mice exposed to female mice (Same Arena group; Fig. 2 B) spent more time at the females' location during the experience and recall trials in the compart- 


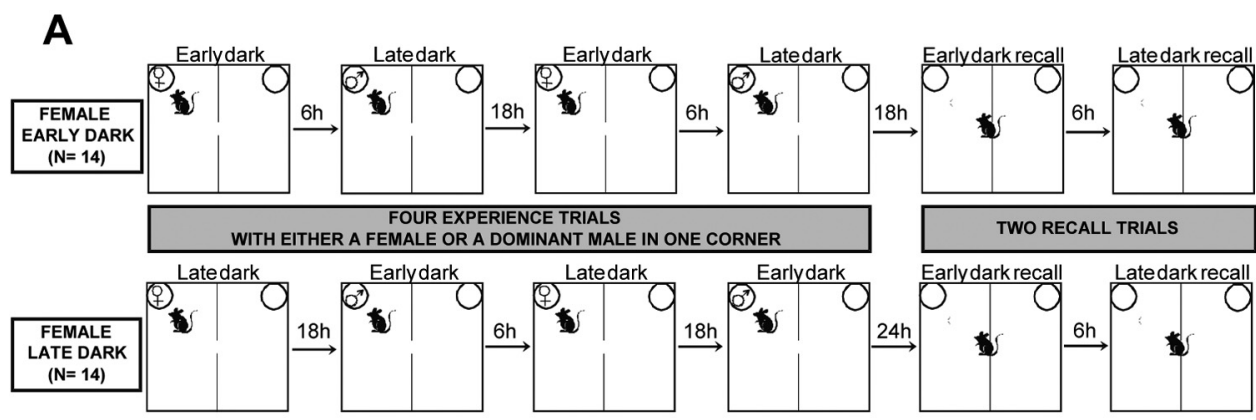

B

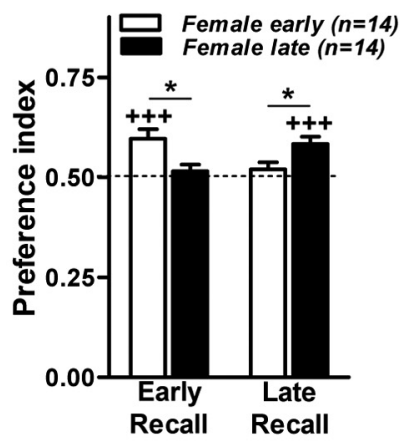

C

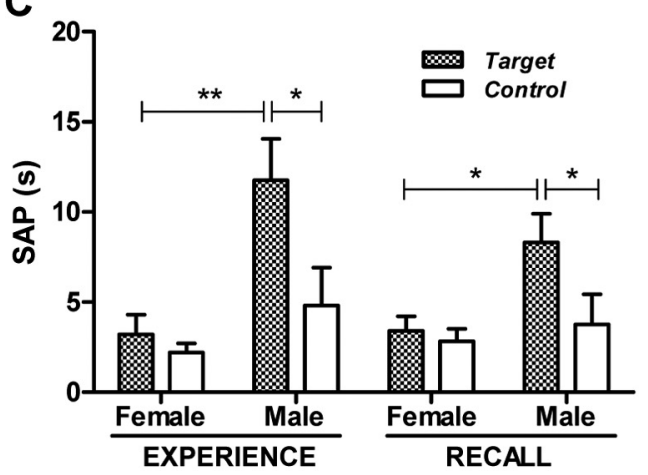

Figure 3. Memory of when. Mice show a preference for the location previously occupied by a female or dominant male only at the time of the day when they had encountered the female. $\boldsymbol{A}$, Two groups of C57BL/6J mice were tested for their ability to recall the time of the day when they encountered either a female or a dominant male mouse (Female Early Dark, $n=14$; Female Late Dark, $n=14$ ). The preference for the location of the female and dominant male was calculated during two recall trials performed in the morning (Early Recall) and in the evening (Late Recall). The mouse drawn in $\boldsymbol{A}$ indicates the starting position in each trial. $\boldsymbol{B}$, Preference index, during the recall trials, for the location previously occupied by the female or dominant male. ${ }^{*} p<0.05$ (Newman-Keuls post hoc after two-way ANOVA for repeated measurements); ${ }^{+++} p<0.001$ (Wilcoxon signed rank test) compared with chance level of 0.5 (depicted with a dashed line in $\boldsymbol{B}$ ). $\boldsymbol{C}$, Time spent in $S A P$ toward the beaker containing the female and dominant male (Target, filled bars) and the empty beaker (Control, empty bars) during the female and dominant male experience trials and during the recall trials performed at time of female and dominant male encounters. Trials at time of female encounters include trials performed in the morning and in the evening with groups Female Early Dark and Female Late Dark, respectively. Trials at time of dominant male encounters include trials performed in the evening and morning with groups Female Early Dark and Female Late Dark, respectively. ${ }^{*} p<0.05$ and ${ }^{* *} p<0.01$ (Newman-Keuls post hoc after two-way ANOVA).

mented arena. Also, CD-1 male mice of the Same Arena group exhibited increased urine marking during the experience and recall trials compared with mice that had been placed in the same arena without a female mouse (No Female group; Fig. $2 \mathrm{~A}$ ), and during the recall trial compared with mice that underwent the recall trial in the open arena (Different Arena group; Fig. 2A). Thus, during the recall trial, the increased time spent at the female's location correlates with greater urine marking behavior, indicating that after a unique experience, male mice memorize what (i.e., the female) was where (i.e., at a specific corner in the arena).

\section{Memory of when (Experiment 3)}

To test whether mice remember when a specific experience occurred, we exposed male mice to a protocol in which they had to associate a specific social stimulus (i.e., a female or a dominant male) with the time of the day during which they had encountered it. Specifically, mice underwent experience trials during which they encountered either a female or a dominant male at the same location in the arena but at different times of the day. C57BL/6J male mice underwent four 20 min experience trials in the compartmented arena: during Trials 1 and 3, a female mouse was placed inside a beaker in a fixed corner of the maze (Female Experience Trial), whereas during Trials 2 and 4, a dominant CD-1 male (by which the C57BL/6J male mice had been previously defeated) was placed in the same beaker in the same corner (Dominant Male Experience Trial). The day after Trials 3 and 4, mice underwent two $10 \mathrm{~min}$ recall trials (one in the early and one in the late hours of the dark phase), during which they showed a time-dependent preference for the target zone previously occupied by a female mouse or a dominant male: mice spent more time at the target zone when the recall trial took place at the same time of day as the Female Experience Trials but not when it was performed at the same time as the Dominant Male Experience Trials (Fig. 3B). To test the hypothesis that mice had whatwhere-when memories of the dominant male encounters, we analyzed a behavior that is expected to be enhanced in the presence of dominant males. Stretched attend posture (SAP) is defined as the elongation of the body into a flat posture, and is considered to be integral component of the risk assessment repertoire of defensive behaviors expressed toward social (Grant and Mackintosh, 1963) and nonsocial (Kaesermann, 1986) anxiogenic stimuli. We scored the expression of SAP toward the target and control beakers during the first 5 min of the experience and recall trials using the software The Observer (Noldus), as described previously (Freitag et al., 2003). We found that time spent in SAP toward the target beaker was enhanced during the Dominant Male Experience Trials compared with the Female Experience Trials (Fig. 3C). During the recall trials, mice spent more time in SAP toward the target beaker at the time of Dominant Male Experience, suggesting that their behavior was based on a conjunctive what-where-when memory.

\section{Role of the hippocampus}

We then monitored whether the expression of mRNA for Arg3.1, an immediate early gene specifically activated during learning 
events and required for memory consolidation (Huff et al., 2006), was activated in the hippocampus $20 \mathrm{~min}$ after termination of the $20 \mathrm{~min}$ experience trial. By means of real-time RT-PCR, we found that mRNA for Arc/Arg3.1 was upregulated in the hippocampus but not in the cerebellum of mice undergoing the experience trial compared with mice exposed to an open field or to female mice introduced in their home cage (Fig. 4A). To prove that the hippocampus is not only activated by the experience trial but that it is also required for memory consolidation, we performed bilateral stereotactic injection of the amnesic drug anisomycin (Squire et al., 1974; Canal et al., 2007; Sharma et al., 2012) into the CA1 region of the dorsal hippocampus of mice immediately after they had undergone the experience trial. Twenty-four hours later, mice injected with anisomycin did not show any spatial bias during the recall trial and spent less time at the female's location compared with salineinjected mice (Fig. 4B).

\section{Discussion}

Using an ecologically relevant paradigm for spontaneous learning, we found that mice create episodic-like memories of unique experiences and that this function requires the hippocampus. Specifically, we showed that these memories in mice fulfill the criteria for episodic-like memory and share similarities with human episodic memory. In fact, the what and where components of the memory were not retrieved based on familiarity and the when component was not processed based on how long ago the event occurred. Importantly, during memory retrieval, the behavior of the mice resulted from the use of the conjunctive whatwhere-when component of the episodic-like memory.

Throughout our study, we used enhanced occupancy of the target zone as discriminatory parameter for memory. Because the expression of a spatial preference may not necessarily mean that an animal behaves based on what-where memories (Griffiths et al., 1999; Clayton et al., 2003b), we searched for other behavioral responses that could be interpreted as induced by the memory of the social stimulus that had been associated with the target position. In Experiment 2, we quantified urine marking behavior because it has been shown that male mice do more urine marks in arenas occupied by female conspecifics (Reynolds, 1971; Maruniak et al., 1975). As expected, urine marks were enhanced when a female mouse was present in the arena. During the recall trial, intense urine marking was displayed only by mice exposed to the same arena in which they encountered the female. These results confirm the idea that the spatial preference shown by mice during the recall trial was based on a conjunction of what-where memories. Urine marking is strongly inhibited in submissive mice and in mice that have been defeated by conspecific males (Desjardins et al., 1973). Because mice had been repeatedly defeated by the dominant males, urine marking could not be used to test the memory for "what" in Experiment 3. We therefore decided to analyze $\mathrm{SAP}$ - a behavior displayed by male mice during risk assessment toward aggressive male mice (Grant and Mackintosh, 1963). During the experience trials, mice did more SAP toward the beaker containing the dominant male mouse. The observation that

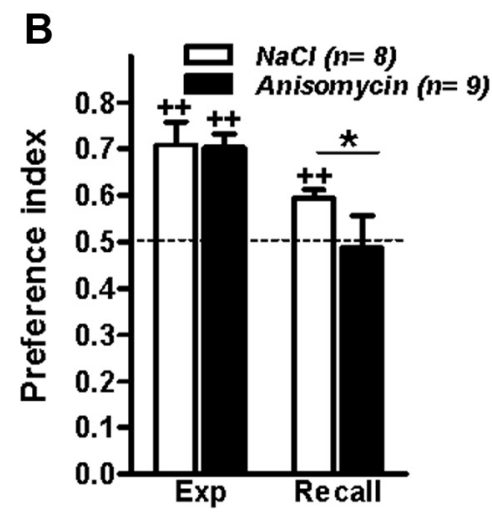

Open field $(n=7,5)$

Female $(n=7,9)$

Experience $(n=12,11)$

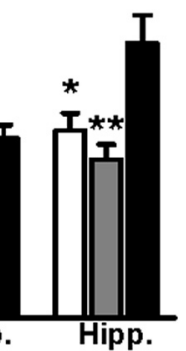

ereb.) and hippocampus (Hipp.) of C57BL/6J mice undergoing an experience trial in the compartmented arena (Experience), an open field (0pen Field), or exposed to female mice introduced into a compartment of their home cages (Female). For each brain region, values are expressed as percentage of the Open Field group. ${ }^{*} p<0.05 ;{ }^{* *} p<0.01$ (Dunn's multiple comparisons after Kruskal-Wallis test) with chance level of 0.5 (depicted with a dashed line).

during the recall trials SAP was the highest toward the target beaker at the time of dominant male encounters supports the hypothesis that mice had a memory of what (the dominant male) was encountered where (at the target beaker) and when (at a specific time of the day).

The temporal component is particularly crucial to define episodic-like memory, and it has been argued that to share qualities similar to human episodic memory, the evaluation of the temporal information should be based on the absolute time when an event occurred (Staddon, 1984; Clayton et al., 2003b). Recently, Zhou and Crystal $(2009,2011)$ reported that rats can process at which time of the day an experience occurred, and proposed that there is a qualitative similarity between episodiclike memory in rats and human episodic memory. In the present study, during the probe trials, the behavior of the mice differed depending on the time of the day at which the trial was done. The "when" information could not be retrieved based on the last experience or the elapsed time since the mouse encountered a female or a dominant male. Thus, mice are capable of processing temporal information based on when a certain experience occurred, at least in terms of time during the day. This is an interesting result because presently available paradigms for episodic-like memory in mice require that the subject identifies the least recently visited place, so it was not possible to define how mice process the temporal component of their memories (Dere et al., 2005).

Clayton and colleagues (2003a) argued that recollecting what happened where and when is not sufficient to confirm the species' capability of creating episodic-like memories. They propose that two further criteria should be fulfilled: the what-wherewhen content should form an integrated representation, and the memory should involve the flexible use of information. The fact that the memories of two different experiences share the same where component (the female and the dominant male were located in the same corner) but evoke different behaviors indicates that the memories correspond to two separate representations integrating the what-where-when components, therefore fulfilling this specific criterion for episodic-like memory. Based on the present data, we cannot definitely say whether mice can make flexible use of their memories, as was shown in scrub jays (Clay- 
ton et al., 2003b). However, the fact that memories are spontaneously created with neither immediate nor foreseeable advantage for the animal suggests that mice constantly grab relevant information from the environment that will eventually be used in a flexible way in the future, allowing proper context-dependent behavioral responses.

It has been shown that the hippocampus is required for episodic memories in humans (Nadel et al., 2000) and in spatial learning and memory in mice (Burgess et al., 2002). Consequently, it is plausible that the hippocampus is involved in the one-trial acquisition and memory consolidation of the female's location in the present paradigm. To test this hypothesis, we monitored whether the experience trial resulted in activation of mRNA for Arc/Arg3.1 expression, an immediate early gene specifically activated during learning events and required for memory consolidation (Huff et al., 2006). We found that mRNA for Arc/Arg3.1 was upregulated in the hippocampus, but not in the cerebellum, of mice undergoing the experience trial when compared with mice exposed to either an open field or to female mice introduced in their home cage. Also, mice injected with anisomycin into the hippocampus after the experience trial did not show any spatial bias during the recall trial and spent less time at the females' positions compared with saline-injected mice. Regardless of the molecular and cellular mechanisms by which amnesia was induced (Squire et al., 1974; Canal et al., 2007; Sharma et al., 2012), because of the specific action of anisomycin at the site of stereotactic injection, it can be stated that the dorsal hippocampus plays a pivotal role during the processing and consolidation of relational and contextual representations in rodents.

In conclusion, the present observations indicate that mice spontaneously generate what-where-when representations of single events and encourage the use of this species for the investigation of neuronal and cellular processes underlying episodic memory in humans and its degeneration in neurological and neuropsychiatric disorders. The strength of our study is the straightforward interpretation of the results that was possible thanks to the fact that the behavioral paradigm and analysis were designed taking in consideration the biology of the mouse. Moreover, the fact that learning occurs spontaneously (i.e., in the absence of punishments or rewards) within one trial and with the absence of anxiogenic or stressful stimuli, makes this paradigm a valuable alternative to commonly used tests for cognition in rodents.

\section{References}

Bronson FH (1976) Urine marking in mice: causes and effects. In: Mammalian olfaction, reproductive processes, and behavior (Doty RL, ed), pp 119-141. New York: Academic.

Burgess N, Maguire EA, O’Keefe J (2002) The human hippocampus and spatial and episodic memory. Neuron 35:625-641. CrossRef Medline

Canal CE, Chang Q, Gold PE (2007) Amnesia produced by altered release of neurotransmitters after intraamygdala injections of a protein synthesis inhibitor. Proc Natl Acad Sci U S A 104:12500-12505. CrossRef Medline

Clayton NS, Dickinson A (1998) Episodic-like memory during cache recovery by scrub jays. Nature 395:272-274. CrossRef Medline

Clayton NS, Yu KS, Dickinson A (2003a) Interacting cache memories: evidence of flexible memory use by scrub jays. J Exp Psychol Anim Behav Process 29:14-22. CrossRef Medline

Clayton NS, Bussey TJ, Dickinson A (2003b) Can animals recall the past and plan for the future? Nat Rev Neurosci 4:685-691. CrossRef Medline

Dere E, Huston JP, De Souza Silva MA (2005) Episodic-like memory in mice: simultaneous assessment of object, place and temporal order memory. Brain Res Brain Res Protoc 16:10-19. CrossRef Medline

Dere E, Huston JP, De Souza Silva MA (2007) The pharmacology, neuro- anatomy and neurogenetics of one-trial object recognition in rodents. Neurosci Biobehav Rev 31:673-704. CrossRef Medline

Desjardins C, Maruniak JA, Bronson FH (1973) Social rank in house mice: differentiation revealed by ultraviolet visualization of urinary marking patterns. Science 182:939-941. CrossRef Medline

Fellini L, Morellini F (2011) Geometric information is required for allothetic navigation in mice. Behav Brain Res 222:380-384. CrossRef Medline

Fellini L, Schachner M, Morellini F (2006) Adult but not aged C57BL/6 male mice are capable of using geometry for orientation. Learn Mem 13:473481. CrossRef Medline

Ferkin MH, Combs A, delBarco-Trillo J, Pierce AA, Franklin S (2008) Meadow voles, Microtus pennsylvanicus, have the capacity to recall the "what," "where," and "when" of a single past event. Anim Cogn 11:147159. CrossRef Medline

Franklin KBJ, Paxinos G (1997) The mouse brain in stereotaxic coordinates. San Diego: Academic.

Freitag S, Schachner M, Morellini F (2003) Behavioral alterations in mice deficient for the extracellular matrix glycoprotein tenascin-R. Behav Brain Res 145:189-207. CrossRef Medline

Grant EW, Mackintosh JH (1963) A comparison of the social postures of some common laboratory rodents. Behaviour 21:246-259. CrossRef

Griffiths D, Dickinson A, Clayton N (1999) Declarative and episodic memory: what can animals remember about their past? Trends Cogn Sci 3:7480. CrossRef Medline

Huff NC, Frank M, Wright-Hardesty K, Sprunger D, Matus-Amat P, Higgins E, Rudy JW (2006) Amygdala regulation of immediate-early gene expression in the hippocampus induced by contextual fear conditioning. J Neurosci 26:1616-1623. CrossRef Medline

Hurst JL (1989) The complex network of olfactory communication in populations of wild house mice Mus domesticus rutty: urine marking and investigation within family groups. Anim Behav 37:705-725. CrossRef

Hurst JL (1990) Urine marking in populations of wild house mice Mus domesticus rutty. III. Communication between the sexes. Anim Behav 40: 233-243. CrossRef

Kaesermann HP (1986) Stretched attend posture, a non-social form of ambivalence, is sensitive to a conflict-reducing drug action. Psychopharmacology 89:31-37. Medline

Maruniak JA, Darney KJ, Bronson FH (1975) Olfactory perception of the nonsocial environment by male house mice. Behav Biol 14:237-240. CrossRef Medline

Meier I, Fellini L, Jakovcevski M, Schachner M, Morellini F (2010) Expression of the snoRNA host gene gas 5 in the hippocampus is upregulated by age and psychogenic stress and correlates with reduced novelty-induced behavior in C57BL/6 mice. Hippocampus 20:1027-1036. CrossRef Medline

Nadel L, Samsonovich A, Ryan L, Moscovitch M (2000) Multiple trace theory of human memory: computational, neuroimaging, and neuropsychological results. Hippocampus 10:352-368. CrossRef Medline

Parmigiani S, Palanza P, Rogers J, Ferrari PF (1999) Selection, evolution of behavior and animal models in behavioral neuroscience. Neurosci Biobehav Rev 23:957-969. CrossRef Medline

Reynolds E (1971) Urination as a social response in mice. Nature 234:481483. CrossRef Medline

Sharma AV, Nargang FE, Dickson CT (2012) Neurosilence: profound suppression of neural activity following intracerebral administration of the protein synthesis inhibitor anisomycin. J Neurosci 32:2377-2387. CrossRef Medline

Squire LR, Kuczenski R, Barondes SH (1974) Tyrosine hydroxylase inhibition by cycloheximide and anisomycin is not responsible for their amnesic effect. Brain Res 82:241-248. CrossRef Medline

Staddon JE (1984) Time and memory. Ann N Y Acad Sci 423:322-334. CrossRef Medline

Tulving E (1972) Episodic and semantic memory. In: Organization of memory (Tulving E, Donaldson W, eds), pp 381-403. New York: Academic.

Tulving E (2002) Episodic memory: from mind to brain. Annu Rev Psychol 53:1-25. CrossRef Medline

Zhou W, Crystal JD (2009) Evidence for remembering when events occurred in a rodent model of episodic memory. Proc Natl Acad Sci U S A 106:9525-9529. CrossRef Medline

Zhou W, Crystal JD (2011) Validation of a rodent model of episodic memory. Anim Cogn 14:325-340. CrossRef Medline 